\title{
An explanation from customers' perspectives for difficulties in developing nursing-home service in Vietnam - A study in Ho Chi Minh City
}

\author{
Le Thi Thanh Xuan ${ }^{1 *}$, Nguyen Phuong Thuy Linh ${ }^{1}$
}

${ }^{1}$ School of Industrial Management, Ho Chi Minh City University of Technology, Vietnam

${ }^{*}$ Corresponding author: 1ttxuan@hcmut.edu.vn

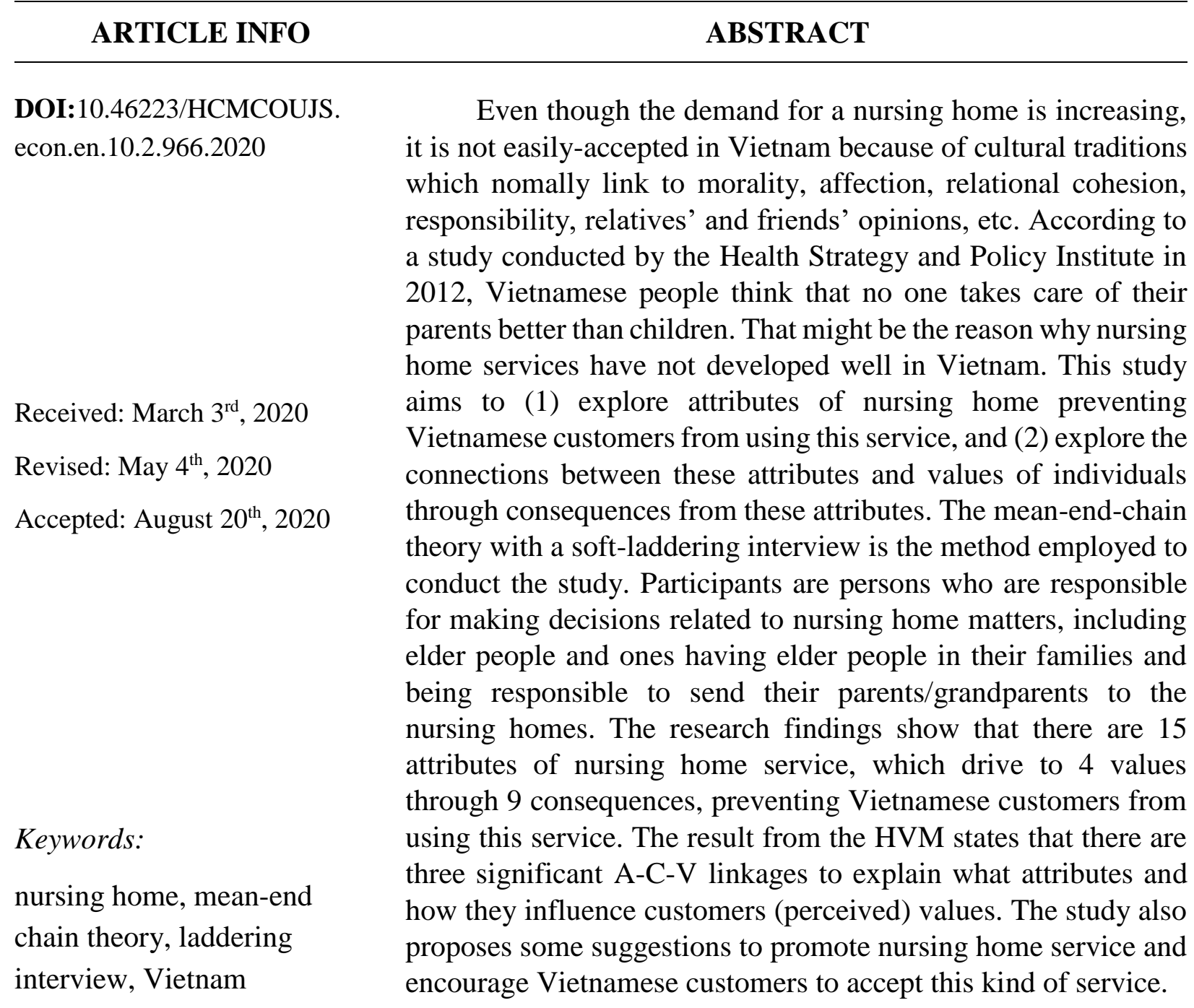

\section{Introduction}

A nursing home is, as defined by the US National Institute on Aging, a place for people who do not need to be in a hospital but cannot be cared at home (Medilineplus, n.d.). Mostnursing homes provide nursing aides and skilled nurses on hand 24/7 and they are specialized in medical care, as well as physical, speech, and occupational therapy, or have special care units for people with serious problems such as Alzheimer's disease, diabetes, etc. Moreover, nursing homes also provide long-term care for residents, often elderly, who are no longer capable of taking care of themselves. It can be the last stop in a continuum of senior care that ranges from living on one's own to living in a nursing home. In the globe, there have been some studies on the importance of 
nursing homes. For example, Covinsky et al. (1994) studied how serious illness of patients impacts their families, or McMillan and Mahon (1994) investigated the burden on caregivers, etc.

Vietnam is one of the most rapidly aging countries with the population which has entered the 'aging phase' since 2011 (NDO, 2017). The ratio of elderly persons in the total population is 11.9 percent. The percentage of people who are over 60 has increased significantly yearly, therefore, approaches in health care, retirement age, pension, social interaction, and intergenerational relations are required to be changed (Vietnambreakingnews, 2018). Elderly people have faced a variety of diseases which are required lifelong treatment, such as high blood pressure, stroke, diabetes, cancers, and asthma. Apart from that, they are also dealing with Alzheimer's malnutrition and depression. The reduction of daily activities worsens health conditions for the elderly, and therefore, the idea of a nursing home should be accepted and taken into consideration as a last resort. However, in Vietnam, the 'nursing home' remains a prejudiced concept since most Vietnamese families look after old parents in their own homes, and the actions of sending the older people to the nursing home are commonly seen as unethical and irresponsible, a failure to perform a filial duty, or a lack of respect for elders. Therefore, the concept of a nursing home has not been accepted widely, even though it is not new to Vietnamese people.

An overview of the nursing-home sector shows that most of the nursing homes have to shut down their operations or change to other types of business (People'sArmyNewspaper, 2017). One example is Ba Thuong nursing home center, opening in 2007 as the first private nursing home in Hochiminh city to offer "European standards", such as green spaces, through services and decent infrastructure for customers, which has been changed its functions to provide accommodation for short-term and long-term tourists. Other examples are Eden Nursing Home, and Binh My Nursing Home, which were also closed due to their inefficient businesses.

In such circumstances, the mindset towards nursing home service of Vietnamese people needs to be changed, and services and resources to take care of elderly people, including human resources with appropriate specialization, infrastructure, policies, ... should be available from now. This study aims to uncover the reasons preventing Vietnamese customers from using this service with the following research questions: (1) what are attributes of nursing home service preventing Vietnamese people from using this service?; (2) What are the connections between these attributes and values of individuals through consequences?

The study is conducted in Hochiminh city, the largest city with the highest population in Vietnam, and focuses on families having elderly persons from 60 and over. The interviewees, elderly persons, and ones who have the right to make a decision whether to send elderly persons to the nursing homes are approached and interviewed by the soft-laddering method in means-end chain (MEC) theory.

\section{Literature review}

\subsection{An overview of the nursing home service}

In general, the nursing home has some characteristics in its operation as follows: Firstly, its supports elderly people in activities of daily living, for example, the functional mobility, including the ability to walk or transfer from the wheelchair to another surface and back again; or the dressing, toileting, etc.

Secondly, it also provides specialized medical care and rehabilitation services to individuals who need 24-hour medical supervision. Short-term or long-term care is required depending on the status of patients, including the ones getting a stroke, Parkinson's disease, 
surgery, infection, and general wound care. Therefore, skilled nursing care is needed to perform physical therapy, intravenous injections, or other medical care administration (Senior Path). Lastly, it offers few facilities offering custodial care for individuals who suffer from dementia, including Alzheimer's disease, presented with a decline in memory, language, thinking skills.

A study conducted in Taiwan in 2018 confirmed the above issues. Moreover, Lin, Jeng, and Yeh (2018) also found that elderly respondents appreciate the virtual reality leisure activities that are fun, safe, and easy. For the outcome benefits, elderly respondents highly value a sense of physical and mental well-being, self-directed learning experience, and satisfying curiosity. In terms of value, elderly respondents expect that entertainment activities would improve not only their connections with others, but also their pleasure, quality of life, and sense of acceptance. Although consumers have various decision-making processes on leisure activities, the terminal value which has been shared is building "good memories". This gives a potential opportunity to promote virtual reality leisure activities. Relevant institutions or service providers can seek to create good memories in consumers by developing activities that are safe and fun, good for health, and offer good service, thereby attracting the interest of elderly consumers.

\subsection{Nursing home service in Vietnam}

There is no official documented data or report of nursing home service in Vietnam. However, a review of some webpages of nursing home service, such as Binh My Nursing home or Vuon Lai Nursing home, shows that, currently, nursing homes in Vietnam present various types of service such as home care, daycare service, short-term care service, long-term care service, special care for persons getting health problems. For example, home care service is provided with skilled nurses that help the sick person get well, heal quickly, and reduce the risk of complication; or for people just want to seek the environment for activities and communication with peers while relatives are at work or school, daycare service is a choice. With this model, elderly people still live with their children, but at the same time, they do not feel lonely when their family members go to work and school, ...

\subsection{Previous studies on nursing home}

This section reviews previous studies in the globe related to the nursing home. The review shows that nursing home is not much explored in the context of developing countries like Vietnam, but the developed ones. Some studies were conducted in developed countries, such as Finland, German, etc. For example, Tuominen, Leino-Kilpi, and Suhonen (2016) studied about the free will of older people who live in a nursing home in Finland. They found that the freedom level of the older people decrease after moving to the nursing home, where the barriers of free will were originated from the senior people themselves, other residents in the nursing home, the nurses, and the organization.

Another study of M Kellett (2000) found that studied families do not want to be in control but wish to be considered members of the caring team; for some who do not receive support from nursing staff, they felt distressed by their lack of professional knowledge and skills in accommodating changes in their relationship and caring for their relatives. More specifically, Kalinowski, Wulff, Kölzsch, Kopke, Kreutz, and Dräger (2012) focused on finding barriers to and facilitators of physical activity in the nursing homes. The research findings showed that forms of exercise available were not adequately communicated to residents. In addition, a broad range of forms of exercise was generally available but they were rarely tailored to the nursing homes' needs and their effectiveness remains questionable. 
The review shows that there has not been any study conducted to explore the reasons why people do not want to use nursing home services. Meanwhile, understanding these reasons is significant for realizing customers' decision to choose or deny using a product or service. The purchase decisions are strongly affected by personal relevance which is suitably addressed by the means-end approach. Thus, this is trying to find out the barriers from using the nursing home services of the Vietnamese people using MEC approach and aim to contribution to not only enhancing the health of the senior people but also bringing humanity values to society. These above-mentioned findings withdrawn from the studies in other countries will be used as references during the interviews of this study in the context of Vietnam, particularly people who live in Ho Chi Minh City.

\subsubsection{Means-end chain theory}

The Means-End Chain (MEC) theory, originally developed by Gutman (1982), is often applied when the aim is to gain a better understanding of the relationship between consumer knowledge and consumer behavior. It involves analyzing consumer values, which reveal the multiple levels of the cognitive choice structure of decision-makers(as cited in Pitts, Wong, \& Joel Whalen, 1991). "Method" refers to the subjective perception of product attributes held by decisionmakers, while "objective" refers to the values held by individuals. The main purpose of this theory was to understand consumer decision-making and connect the two nodes of methods and objectives to explain consumer behavior (Reynolds \& Olson, 2000). Consumers believe that a choice of specific attributes can help individuals realize desired values. That is, in the consumers' mind, there is a three-element relationship between "attributes" (A), "consequences" (C), and "values" (V) (see Figure 1).

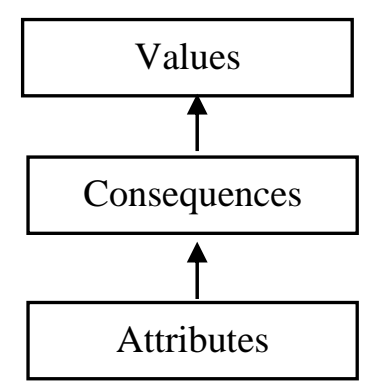

Figure 1. The basic means-end model

Source: Reynolds and Olson (2000)

Moreover, the basic A-C-V matrix is amplified through six levels, separating attributes into concrete and abstract attributes; consequences in functional and psychological; values in instrumental and terminal (Reynolds \& Olson, 2000).

The concrete attributes are defined as properties or characteristics of the product, service, or performance that may be desired or pursued by consumers, while abstract attributes are those that cannot be tested before consumption of the product and must, therefore, be elicited from internal or external information sources. In terms of the consequences, functional consequences are the benefits related to the product attributes that consumers directly and immediately experience from having products or services, normally during or soon right after the consumption, and psychosocial consequences are the results of a more personal, social, and less tangible nature. The instrumental values are intangible goals associated with the behavioral means used to achieve the end purposes, and finally, terminal values refer to desired end states (Walker \& Olson, 1991). 
However, most researchers agree that the six-level model is complex and unnecessary for most applications in both business and theoretical purposes. The four-level one then becomes the "standard" or the most common model to be applied (Reynolds \& Olson, 2000) (see Figure 2).

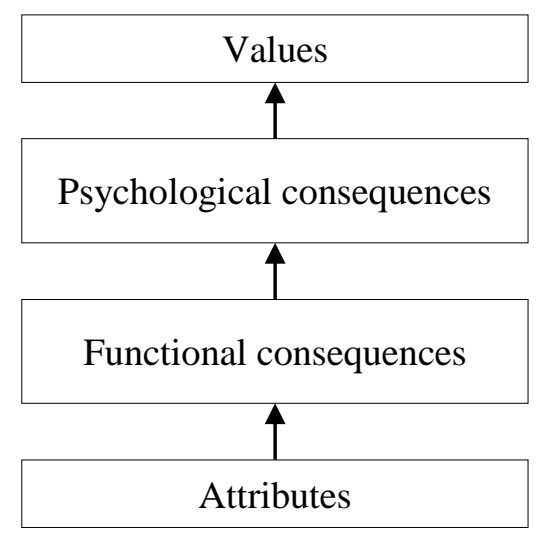

Figure 2. The four-level means-end model

Source: Reynolds and Olson (2000)

\subsubsection{Laddering interview}

Laddering is the earliest method of collecting qualitative data within MEC (Grunert \& Grunert, 1995). The one-on-one interview techniques are used to understand how consumers use product attributes to satisfy their values, the interview process requires in-depth exploration to discover the values that consumers desire. The purpose of the interviews was to reveal an individual's motivation for choosing a specific product. This method is most suited to small or intermediate sample size (Grunert \& Grunert, 1995).

Laddering interviews can be divided into soft-laddering and hard-laddering (Grunert \& Grunert, 1995). Soft-laddering is carried out by in-depth one-on-one interviews applying an open question approach, that allows respondents to give unlimited answers and using free elicitation methods to get information. Soft-laddering analysis requires a sample size of at least 20 (Reynolds \& Olson, 2000), but it is not suitable for collecting a large sample (ter Hofstede, Audenaert, Steenkamp, \& Wedel, 1998). Hard-laddering can be implemented via telephone, e-mail, or selfadministered questionnaires to obtain information on the hierarchical order of attributes, consequences, and values through respondents' answers. This method requires a large sample size, usually more than fifty (ter Hofstede et al., 1998).

\section{Methodology}

The purpose of this study is to explore the reasons why Vietnamese people are reluctant to use a nursing home service. Therefore, this study employs MEC theory with a soft-laddering interview as the method to collect data. The objective is to explore the attributes of nursing home service consequences from these attributes and values impacted by these consequences from customers' perspectives. The flow of questions is to start with the question "From your point of view, what are attributes of current nursing home service in Vietnam preventing you/your family from using this service?"; then Why questions are followed to explore the consequences of every attribute. Interviews finish when respondents come to the end of chains that link to (individual) values, even directly or indirectly.

The sampling method is purposive with respondents who are (1) elderly people have heard about the nursing home but do not use its services and/or family members who have heard about the nursing home but do not send elder to the nursing home; (2) elderly people used to live in the 
nursing home before and/or members in a family which has elder not living in the nursing home any longer. Referring to the guidance of Reynolds \& Gutman (1988), data collection and analysis are performed according to Association Pattern Technique (APT). As stated by ter Hofstede et al. (1998), the integration between APT and the Means-end chain theory was successfully applied in several studies in the world.

\section{Research findings}

In total, there are 21 respondents interviewed, including 08 elderly persons and 13 relatives (who have a decisive role in sending their senior persons to the nursing home), respectively. There are only 3 men approached in this study compared to 18 women. In the senior group, respondents can be categorized into 03 groups of 60-69 ages, 70-79 ages, and 80 or above with the percentage of $37.5 \%, 50 \%$, and $12.5 \%$, respectively. Meanwhile, in the group of relatives, information of elderly people in their families was also collected, and the proportion of the senior people are quite same as that in the senior group whose ages of 60-69 are 38\% of the total while 70-79 years old occupy $54 \%$, and the rest $8 \%$ falls into 80 years or above.

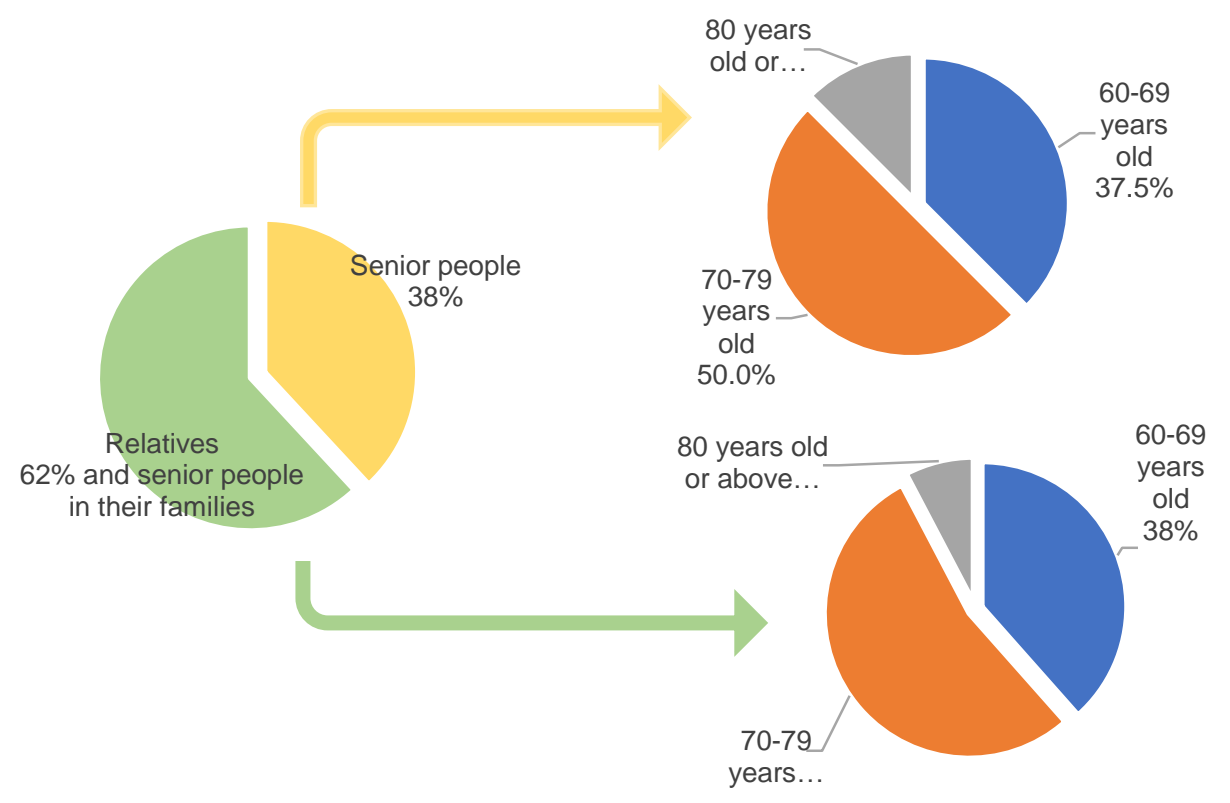

Figure 3. The description of the respondents categorized by age

\subsection{List of Attributes (A), Consequences (C), and Values (V)}

The interview process was carried out in the form of face-to-face with the technique of soft-laddering interview. Through the interviews, many reasons which are considered resistances to using the nursing home services of Vietnamese people are revealed. Then, a summary list of codes reflecting all opinions mentioned in the interview was developed. There are 15 attributes, 09 consequences (05 functional and 04 psychological ones), and 04 values explored from the interviews.

The codes were classified into three basic A, C, V levels and described in the table below. 


\section{Table 1}

The list of attributes, consequences, and values explored from the interviews

\begin{tabular}{|c|c|}
\hline & List of Attributes \\
\hline \multirow{15}{*}{ Attributes } & A1 - A new environment with many strangers \\
\hline & A2 - An Isolated location \\
\hline & A3 - A crowded place \\
\hline & A4 - A place with regulations and schedule to comply \\
\hline & A5 - A high/expensive cost \\
\hline & A6 - A place with uniform required \\
\hline & A7 - Living with people having different circumstances and personalities \\
\hline & A8 - A place with sick persons \\
\hline & A9 - Lacking recreational activities \\
\hline & A10 - Having not-good/clean facilities \\
\hline & A11 - Limited expertise in geriatric diseases \\
\hline & A12 - Poor performance of staff (including proficiency and attitude) \\
\hline & A13 - Being forced to eat \\
\hline & A14 - Dietary matters are not guaranteed \\
\hline & A15 - Individual needs cannot be met \\
\hline \multicolumn{2}{|r|}{ List of Consequences } \\
\hline \multirow{4}{*}{$\begin{array}{c}\text { Functional } \\
\text { Consequences }\end{array}$} & C1 - Difficulties to meet and engage with relatives and friends \\
\hline & C2 - Unable to control my life (Cannot do what I like) \\
\hline & C3 - Cannot connect and harmonize with people in the nursing home \\
\hline & $\mathrm{C} 4$ - It costs a lot of money \\
\hline \multirow{5}{*}{$\begin{array}{l}\text { Psychological } \\
\text { Consequences }\end{array}$} & C5 - The health of the elderly is affected \\
\hline & C6 - Be worried, uncomfortable \\
\hline & C7 - Feeling sad, lonely \\
\hline & C8 - Do not trust the quality of service \\
\hline & C9 - Elderly person gets hurt/abused \\
\hline \multicolumn{2}{|r|}{ List of Values } \\
\hline \multirow{4}{*}{ Values } & V1 - No assurance (feeling hurt) \\
\hline & V2 - Lack of freedom \\
\hline & V3 - Financial matter \\
\hline & V4 - Dissatisfaction \\
\hline
\end{tabular}




\subsection{Constructing the HVM}

According to MEC theory (Reynolds \& Gutman, 1988), there are two types of relations between elements: direct relations which refer simply to the sequential order within the ladder; and indirect relation. This study employs the option in constructing the overall matrix of relations among elements. Table 2 presents the row-column frequency matrix indicating the number of times, directly and indirectly, all row elements lead to all column elements.

The chain relationships between the collected attributes, consequences, and values formed by laddering are shown by the numbers in the matrix. The larger the number, the more link appearances in the interviews, and therefore, the number indicates the strength of the linkages. In the matrix, the links between attributes and consequences are shown in the matrix column, and those between consequences and values are shown in the matrix row (Reynolds \& Olson, 2000). The numbers before the symbol (;) demonstrate the frequency of direct chain relations between the factors, while the numbers after the symbol demonstrate the frequency of indirect chain relations.

Table 2

Summary Implication matrix*

\begin{tabular}{|c|c|c|c|c|c|c|c|c|c|c|c|c|c|c|}
\hline & C1 & C2 & C3 & C4 & C5 & C6 & C7 & C8 & C9 & V1 & V2 & V3 & V4 & Total \\
\hline A1 & & $1 ; 0$ & $2 ; 0$ & & & $\mathbf{3 ; 1}$ & $1 ; 0$ & & & $0 ; 4$ & & & $0 ; 3$ & $7 ; 8$ \\
\hline A2 & $\mathbf{4 ; 0}$ & & & & & & & & & $0 ; 2$ & & & $0 ; 2$ & $4 ; 4$ \\
\hline A3 & & & & & & $\mathbf{4 ; 0}$ & & & & $0 ; 2$ & & & $0 ; 2$ & $4 ; 4$ \\
\hline A4 & $2 ; 0$ & $\mathbf{4 ; 0}$ & & & & & & & & & $0 ; 2$ & & $0 ; 3$ & $6 ; 5$ \\
\hline A5 & & & & $\mathbf{5 ; 0}$ & & & & & & & & $0 ; 5$ & & $5 ; 5$ \\
\hline A6 & & & & & & $2 ; 0$ & & & & & $0 ; 2$ & & & $2 ; 2$ \\
\hline A7 & & & $\mathbf{1 0 ; 0}$ & & & $2 ; 1$ & $0 ; 1$ & & & $0 ; 4$ & & & $0 ; 8$ & $12 ; 14$ \\
\hline A8 & & & & & $1 ; 0$ & $1 ; 0$ & & & $0 ; 1$ & & & $0 ; 1$ & $2 ; 2$ \\
\hline A9 & & $1 ; 0$ & $\mathbf{3 ; 0}$ & & & & $\mathbf{4 ; 2}$ & & & & & & $0 ; 8$ & $8 ; 10$ \\
\hline A10 & & & & & $\mathbf{6 ; 0}$ & $1 ; 0$ & & & $0 ; 6$ & & & $0 ; 1$ & $7 ; 7$ \\
\hline A11 & & & & & $\mathbf{3 ; 0}$ & $\mathbf{3 ; 2}$ & & $2 ; 0$ & & $0 ; 7$ & & & $0 ; 1$ & $8 ; 10$ \\
\hline A12 & & & $\mathbf{3 ; 0}$ & & $2 ; 0$ & $\mathbf{3 ; 2}$ & $0 ; 2$ & $\mathbf{7 ; 0}$ & $1 ; 0$ & $0 ; 9$ & & & $0 ; 5$ & $16 ; 18$ \\
\hline A13 & & & & & & & & & $1 ; 0$ & & & & $0 ; 1$ & $1 ; 1$ \\
\hline A14 & & & & & $\mathbf{5 ; 0}$ & $1 ; 1$ & & & & $0 ; 4$ & & & $0 ; 2$ & $6 ; 7$ \\
\hline A15 & & & & & & $2 ; 0$ & $2 ; 0$ & & & $0 ; 1$ & & & $0 ; 3$ & $4 ; 4$ \\
\hline C1 & & & & & & & & & & $2 ; 0$ & & & $4 ; 0$ & $6 ; 0$ \\
\hline C2 & & & & & & $1 ; 0$ & & & & $2 ; 0$ & & $3 ; 1$ & $6 ; 1$ \\
\hline C3 & & & & & & $2 ; 0$ & $3 ; 0$ & & & $2 ; 2$ & & & $10 ; 3$ & $17 ; 5$ \\
\hline
\end{tabular}




\begin{tabular}{|c|c|c|c|c|c|c|c|c|c|c|c|c|c|c|}
\hline & C1 & C2 & C3 & C4 & C5 & C6 & C7 & C8 & C9 & V1 & V2 & V3 & V4 & Total \\
\hline C4 & & & & & & & & & & & & $5 ; 0$ & & $5 ; 0$ \\
\hline C5 & & & & & $3 ; 0$ & & & & $3 ; 3$ & & & $2 ; 0$ & $8 ; 3$ \\
\hline C6 & & & & & & & & & $13 ; 0$ & $2 ; 0$ & & $3 ; 0$ & $18 ; 0$ \\
\hline C7 & & & & & & & & & & & & $10 ; 0$ & $10 ; 0$ \\
\hline C8 & & & & & $1 ; 0$ & & & & $6 ; 1$ & & & $1 ; 0$ & $8 ; 1$ \\
\hline C9 & & & & & & $1 ; 0$ & & & & & & $1 ; 1$ & $2 ; 1$ \\
\hline Total & $6 ; 0$ & $6 ; 0$ & $18 ; 0$ & $5 ; 0$ & $10 ; 0$ & $33 ; 7$ & $14 ; 5$ & $9 ; 0$ & $2 ; 0$ & $25 ; 45$ & $4 ; 4$ & $5 ; 5$ & $35 ; 46$ & $172 ; 112$ \\
\hline
\end{tabular}

*No relations exits between the attributes elements

Source: The researcher's data analysis

The Implication matrix (Table 2) shows the number of direct and indirect relationships that appear in the interviews, indicating the relationships between the elements arranged in rows leading to the elements arranged in columns. For instance, the number 3;1 in the cell (A1, C6) indicates that the direct link A1-C6 was checked by 3 respondents, while this link was mentioned indirectly by 1 respondent. In the same way, 10 respondents agreed on the links between A7-C3 described in the cell (A7, C3) in Table 4.6, and there is no indirect link between A7 and C3 created among the interviews. Regarding the relationship between the consequences and values, the number $6 ; 1$ in the cell $(\mathrm{C} 8, \mathrm{~V} 1)$ represents that 6 respondents mentioned to the direct link $\mathrm{C} 8-\mathrm{V} 1$, and only 1 person shared indirect link between them. In the table of the matrix, the higher the number appears, the stronger the links among elements, and vice versa.

From the suggestion of Reynolds and Gutman (1988) about the cut-off of A-C relation (usually from 3-5), this study chooses the cut-off at 3 to develop the HVM (see Figure 4). Therefore, 04 attributes (A6, A8, A13, and A15); 01 consequence (C9); and 01 value (V2) are excluded; and, in Table 2, the chosen A, C, V, and A-C relations are marked in bold and underlined.

\subsection{Discussion}

From the HVM (see Figure 4), there are some crucial findings. Firstly, among 11 attributes in the HVM, there are 05 attributes mentioned by most interviewees, including A7, A9, A10, A11, and A12. Secondly, V1 and V4 are recognized as the significant values perceived by respondents to explain why they do not want to use nursing home service. Lastly, the strongest relations in the HVM include A7-C3-(C7)-V4; A10-C6-V1 and A12-C8-V1.

\subsubsection{Most mentioned attributes}

Among the frequently-mentioned attributes, A7 is the obvious feature of nursing home service, which cannot be changed. When moving to a nursing home, elderly people have to live in a context surrounded by many strangers with different backgrounds. This issue makes them feel uncomfortable and might affect their health badly. However, the remaining 04 attributes A9, A10, A11, and A12 can be improved because they are related to nursing homes' operations.

Firstly, A9 is about the lack of recreational activities, which play a vital role in life and enhance the quality of life. It not only satisfies elderly people's needs but also brings them a lot of benefits to increase their health and fitness. These activities could be gardening, walking, music 
therapy, playing chess, or group exercise classes, etc. If nursing homes lack these recreational works, it would impact adversely on both physical and mental of people living there, and possibly makes people feel upset and lonely. As shared by an interviewee (Mr. Pham Q. P.) whose father spent about one and a half years at Thi Nghe Nursing Center, there were not many leisure activities for the residents. If the center could provide such kind of activities, the elderly people in the nursing homes would have chances to gather, talk, and share, then they can be closer and have a more harmonious life there.

Secondly, A10 is about the poor condition of facilities in nursing homes. Currently, in Vietnam, the nursing home is divided as public and non-public organizations. The public ones are normally established and run as poorhouses with the purpose of helping the lonely elderly people when they are getting old and cannot support their owned lives. This kind of nursing home is funded by Government budget or charity fund, therefore, the facilities are very limited. As shared by an interviewee (his father spent about one and a half year in a public nursing home), the facilities are in very poor conditions, such as slow drainage in the rainy season, humid air, etc.. In another public nursing home, the daily necessities are often in shortages, such as diapers, shower gels, detergent, etc. These make the residents living there feel uncomfortable.

Thirdly, A11 is about the situation of lacking and limiting expertise in geriatric diseases. Presently, in Vietnam, there is only one leading hospital caring specifically for the elderly National Geriatric Hospital. In the provinces, according to the latest statistics, only about $20 \%$ of provincial hospitals have geriatric departments, mostly concentrated in provinces with a large population. Many provincial hospitals have not even established a geriatric department - according to Doctor Tran Van Luc from National Geriatric Hospital. With such a realistic situation, it is normal to worry about the limited expertise in geriatric diseases at a nursing home. This is because when moving to a nursing home, the daily activities as well as beings of senior residents rely on caring from staff and doctor. Moreover, the nursing home is a place gathering lots of elder people, the shortage of experts in terms of quality and quantity is more serious, and that makes people not assured when entering to the nursing home or sending their beloved to the nursing home.

Lastly, A12 mentions the poor performance of staff (including proficiency and attitude). It is clear that staff in the nursing homes are required to train appropriately to care for old people and they play a very important role in bringing people together. According to Mr. Dao Thanh (Vietnam Nurses Association), lacking human resources in the nursing field is the current issue in Vietnam. Notably, they are only qualified at the level of intermediate and primary, the number of nurses with College level or higher accounts for about $4 \%$. These matters drive to the lack and poor quality of nurses significantly impact on the caring process. Dr. Hoang Van Thanh, Former Deputy Director of Administration of Medical Examination and Treatment (Ministry of Health), said that professional and technical training for nurses has not been paid enough attention and the curriculum is not updated and appropriate with the context of Vietnam (Vietnam News, 2019).

\subsubsection{The most concerning values}

\section{V4 - Dissatisfaction}

The strongest direct relationship A7-C3-V4 indicates the consequence of unable to connect and harmonize with other people in the nursing home because each person has his/her personalities and backgrounds. Senior people think that staying in the nursing home means that they have to live with many strangers, particularly when they have dissimilar characteristics or habits, that will make them feel hard to talk and share, and it is very tough for them to get along with. Moreover, 
it takes time for them to adapt to new friends, new environment. Therefore, Dissatisfaction is the value that respondents feel as a result.

In addition, the linkages A12-C3-V4 and A9-C3-V4 also drive to V4 as the linkage A7$\mathrm{C} 3-\mathrm{V} 4$, from the attributes of staff performance and lacking recreational activities. V4Dissatisfaction is the most crucial value impacted if nursing home service is used.

V1 - No assurance

03 strong ladders are driving to V1, including A10-C6-V1, A12-C8-V1, and A14-C5-V1. As discussed in the section Most-mentioned attributes, poor staff performance (A12, including proficiency and attitude) will let people unable to trust the quality of the service, then they cannot be assured to use the service. In addition, the other two ladders (A14-C5-V1 and A10-C6-V1) also lead to V1. As discussed above, from interviewees' perceptions, one of the attributes of current nursing home service in Vietnam is poor facilities. This issue makes customers feel uncomfortable living in nursing homes. Both elderly people and relatives feel worried much of the worse conditions at the nursing homes. Therefore, Vl-No assurance is an important value to explain why Vietnamese customers are not willing to use the nursing home service.

\section{V3 - Financial matter}

The V3-Financial matter is one of the most-concerned values. The HVM shows that the relation between A5-C4-V3 is a moderate linkage from the attribute High cost (A5). The fact is that Vietnam is an average-income country. However, many elderly people are facing the financial problem. Then, cost spending for life is one of the significant concerns as stated by one interviewee "High-cost service will impact economic matter in my family" (Research interview, A relative). Everyone always expects to have a place with acceptable quality at a reasonable price. 


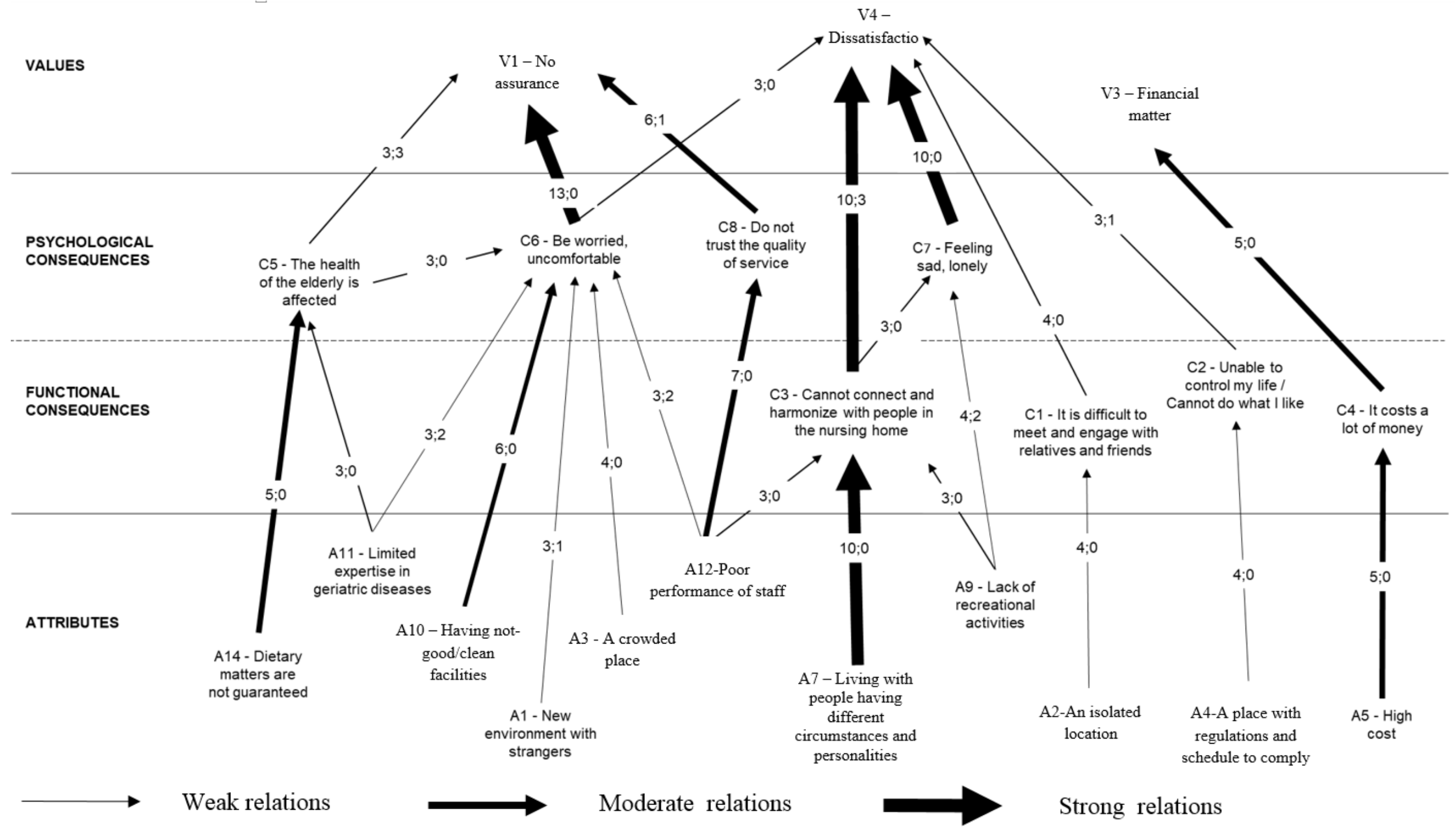

Figure 4. HVM about reasons why Vietnamese people are unwilling to use the nursing home services 


\section{Conclusion}

This study employs the MEC theory with a soft-laddering interview as the method to collect data. In the beginning, there are 15 attributes, 09 consequences (05 functional and 04 psychological ones), and 04 values explored from the interviews. After analyzing, finally, 05 attributes, which are most mentioned form the interviews, through consequences lead to 03 significant individual values (V1-No assurance, V3-Financial matter, and V4-Dissatisfaction). These are considered as the main values resulted from features of current nursing home service in Vietnam preventing customers from using the service.

From the research findings, 05 attributes can be classified into obvious attribute (A7) and operational attributes (A9, A10, A11, and A12). With A7, this attribute cannot be changed because it is an obvious feature of nursing home. With A9, A10, A11, and A12.

\section{Managerial implications}

Therefore, some implications would be suggested to nursing homes to improve their operational attributes:

\section{Training employees working at nursing homes}

The nursing home is not a new concept, but not easily accepted in Vietnam. Therefore, nursing staff, who directly provide caring service to elderly people, especially people with health problems, must be equipped with professional proficiency. It is necessary to classify nursing staff into 02 groups in training: one of the caring givers handling with daily basic tasks, and one of the specialized nurses providing health care and supervising patients's overall health as well as their medical histories. This training practice would make not only senior people but also their relative to be more assured with service quality at nursing homes.

Furthermore, communication is also an important issue in training nursing staff. The main reason is that staff at the nursing homes must be active listeners; they are required to communicate effectively with nursing residents. Elderly people and their relatives would be more assured if nursing homes can have staff working with their fully-understanding and professional knowledge.

\section{Promoting communication about the nursing home to the community}

Up to now, there is not much communication from the nursing home to the community. People can only get information about nursing home through websites or news from the internet, or from acquaintances who have experiences in some cases. The information about the nursing homes might be not correct and as might make people misunderstand this service. Therefore, nursing service providers need to have referral programs through workshops combining with health organizations or elderly groups to disseminate the information of nursing homes as well as available services to the community, thereby helping them become more fully aware of the nursing homes.

\section{Diversifying kinds of nursing services}

It takes time for the nursing home services to be accepted. In the transition time for Vietnamese people to accept nursing home service, more kinds of nursing services should be offered. One example is that, to Vietnamese people, especially the seniors, living with children is an essential desire deeply coming from their hearts. The fact is that adult children are busy with their works and cannot take care of them the whole day long, and they would need a service to take care of in the daytime. Thus, the daycare service of nursing homes can be promoted to meet such needs. Adults can send the parents to nursing homes from the morning to be cared for and to 
join the activities with persons at the same age range to talk and share. In the evening, they will get back home, still meet and gather with their children and grandchildren.

Similar to the above suggestion, each person has his/her demands and expectations, therefore, practical programs or activities should be diversified and offered to groups appropriately. For example, they can be encouraged to learn a new avocation or participate in some classes, etc., which can keep them looking forward to future days. Not only that, nursing home providers can also offer opportunities for them to work or take part in charity programs so they feel they are useful and can still contribute to society.

\section{Limitations and further research}

This study has explored the reasons to explain why the nursing home service is not widely used in Vietnam. The research findings help nursing home providers have a deep look into the current thoughts of customers. However, limitations are still existing, including:

Firstly, the present study approached respondents living in Hochiminh city. Even though Hochiminh city is the biggest city in Vietnam, viewpoints are still limited. An investigation that would extend the sample to other large cities/provinces, such as Hanoi, Danang, Can Tho, etc. to get broader opinions from Vietnamese people of nursing home service.

Secondly, in this study, experts from nursing homes have not interviewed to create a more comprehensive overview of the current market. With such expertized contributions, more features of the nursing homes might be investigated. Future studies should involve experts in this field of studying.

Lastly, a soft-laddering interview is employed to collect data. It is the very first step to explore attributes of nursing home preventing customers from using this service. This method can only approach a small number of respondents to completely analyze and get the meaning of every single information. Future studies should employ hard-laddering interviews to approach a large number of respondents and research findings can be generalized.

\section{References}

Covinsky, K. E., Goldman, L., Cook, E. F., ... Phillips, R. S. (1994). The impact of serious illness on patients' families. SUPPORT investigators. Study to understand prognoses and preferences for outcomes and risks of treatment. JAMA, 272(23), 1839-1844. doi:10.1001/jama.272.23.1839

Grunert, K. G., \& Grunert, S. C. (1995). Measuring subjective meaning structures by the laddering method: Theoretical considerations and methodological problems. International Journal of Research in Marketing, 12(3), 209-225. doi:10.1016/0167-8116(95)00022-T

Kalinowski, S., Wulff, I., Kölzsch, M., Kopke, K., Kreutz, R., \& Dräger, D. (2012). Physical activity in nursing homes - Barriers and facilitators: A cross-sectional study. Journal of Aging and Physical Activity, 20(4), 421-441. doi:10.1123/japa.20.4.421

Lin, C.-S., Jeng, M.-Y., \& Yeh, T.-M. (2018). The elderly perceived meanings and values of virtual reality leisure activities: A means-end chain approach. International Journal of Environmental Research and Public Health, 15(4), Article 663. doi:10.3390/ijerph15040663 
M Kellett, U. (2000). Bound within the limits: Facing constraints to family caring in nursing homes. International Journal of Nursing Practice, 6(6), 317-323. doi:10.1046/j.1440172x.2000.00224.x

McMillan, S.C., \& Mahon, M. (1994). Measuring quality of life in hospice patients using a newly developed Hospice Quality of Life Index. Quality of Life Research, 3, 437-447 doi:10.1007/BF00435396

Medilineplus. (n.d.). Nursing homes. Retrieved February 11, 2020, from https://medlineplus.gov/nursinghomes.html

NDO. (2017, July 17). Seminar shares experiences in adapting to aging population. Retrieved December 20, 2019, from Nhan Dan Online website: https://en.nhandan.com.vn/society/ item/5350702-seminar-shares-experiences-in-adapting-to-aging-population.html Seminar shares experiences in adapting to aging population

People's Army Newspaper. (2017). Ho Chi Minh City lacks elderly care facilities. Retrieved January 20, 2020, from People's Army Newspaper website: https://en.qdnd.vn/socialaffairs/news/ho-chi-minh-city-lacks-elderly-care-facilities-486915

Pitts, R. E., Wong, J. K., \& Joel Whalen, D. (1991). Consumers' evaluative structures in two ethical situations: A means-end approach. Journal of Business Research, 22(2), 119-130. doi:10.1016/0148-2963(91)90046-Z

Reynolds, T. J., \& Gutman, J. (1988). Laddering theory, method, analysis, and interpretation. Journal of Advertising Research, 28(1), 11-31.

Reynolds, T. J., \& Olson, J. C. (2000). Understanding consumer decision making : The meansend approach to marketing and advertising strategy. Mahwah, NJ: Psychology Press.

ter Hofstede, F., Audenaert, A., Steenkamp, J.-B. E. M., \& Wedel, M. (1998). An investigation into the association pattern technique as a quantitative approach to measuring means-end chains. International Journal of Research in Marketing, 15(1), 37-50. doi:10.1016/S01678116(97)00029-3

Tuominen, L., Leino-Kilpi, H., \& Suhonen, R. (2016). Older people's experiences of their free will in nursing homes. Nursing Ethics, 23(1), 22-35. doi:10.1177/0969733014557119

Vietnambreakingnews. (2018). Vietnam faces shortage of qualified geriatric nurses. Retrieved January 20, 2020, from Viet Nam breaking News website: https://www.vietnambreakingnews.com/2018/05/vietnam-faces-shortage-of-qualifiedgeriatric-nurses/

VietnamNews. (2019). Vietnam needs to develop nursing home model. Retrieved January 20, 2020, from Viet Nam breaking News website: https://vietnamnews.vn/society/482286/ viet-nam-needs-to-develop-nursing-home-model.html

Walker, B. A., \& Olson, J. C. (1991). Means-end chains: Connecting products with self. Journal of Business Research, 22(2), 111-118. doi:10.1016/0148-2963(91)90045-Y 